\title{
Генераторы суперконтинуума на основе гольмиевых лазерных систем
}

\author{
В.А. Камынин $^{1}{ }^{* *}$, С.А. Филатова ${ }^{1}$, И.В. Жлуктова ${ }^{1}$, А.И. Трикшев ${ }^{1}$, О.И. Медведков ${ }^{2}$, \\ В.М. Машинский ${ }^{2}$, С.Я. Русанов ${ }^{1}$, В.Б. Цветков ${ }^{1,3}$ \\ ${ }^{1}$ Институт общей физики им. А.М. Прохорова РАН \\ ${ }^{2}$ Научный центр волоконной оптики РАН \\ ${ }^{3}$ Начиональный исследовательский ядерный университет «МИФИ» \\ E-mail: kamyninva@gmail.com
}

DOI:10.31868/RFL2018.82-83

Источники суперконтинуума (СК) ближнего и среднего инфракрасного спектральных диапазонов в последнее время нашли широкое применение в различных областях: спектроскопия [1], метрология, телекоммуникация [2,3], оптическая когерентная томография [4], комб-спектрометры и т.д. Как следствие, разработка сравнительно простых в использовании и мобильных источников широкополосного импульсного излучения остается актуальной задачей. Особый интерес представляют полностью волоконные источники СК, работающие в спектральном диапазоне 2-3 мкм. Стоит отметить, что одной из текущих тенденций в генерации суперконтинуума является реализация "плоских" спектров - спектров с минимальной вариацией амплитуды по спектральному диапазону.

Данная задача может быть успешно решена с использованием импульсных источников на базе оптических волокон, легированных ионами иттербия, эрбия или тулия, однако наибольшие длины волн генерации в волокнах на кварцевой основе могут быть достигнуты с использованием ионов гольмия. Таким образом, используя различные комбинации таких элементов, как задающий импульсный гольмиевый лазер, гольмиевый усилитель и нелинейные волокна можно получить семейство источников с различной длинноволновой границей и спектральной плотностью.

В текущей работе представлены генераторы СК с использованием полностью волоконного гольмиевого лазера, работающего в режиме синхронизации мод (длительность импульса $\sim 1$ пс, центральная длина волны 2.1 мкм), а также несколько каскадов гольмиевых волоконных усилителей и нелинейных сред. Подобные комбинации оптических элементов позволяют получить генерацию СК в спектральном диапазоне от 1.9 до 2.7 мкм.

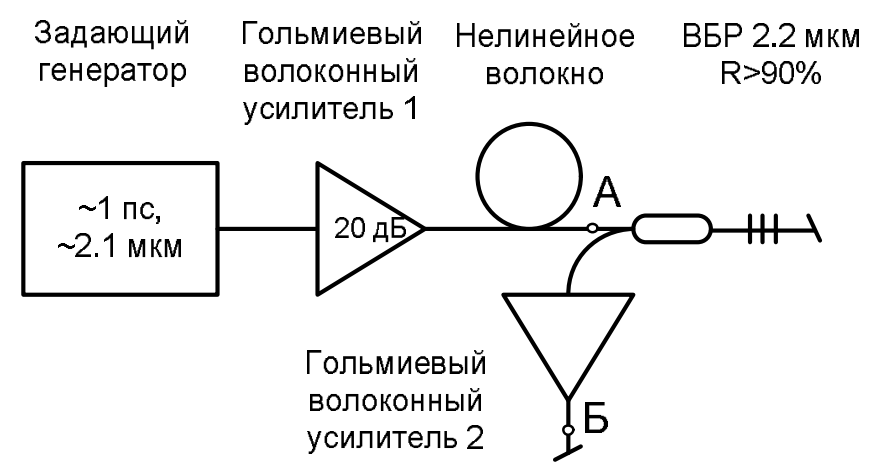

Рис.1 Схема получения импульсного лазерного излучения с длиной волны 2.2 мкм.

Кроме того, использование дополнительных спектрально-селективных элементов в схеме (рис. 1) позволяют выделить последовательности импульсов на определенной длине волны. 

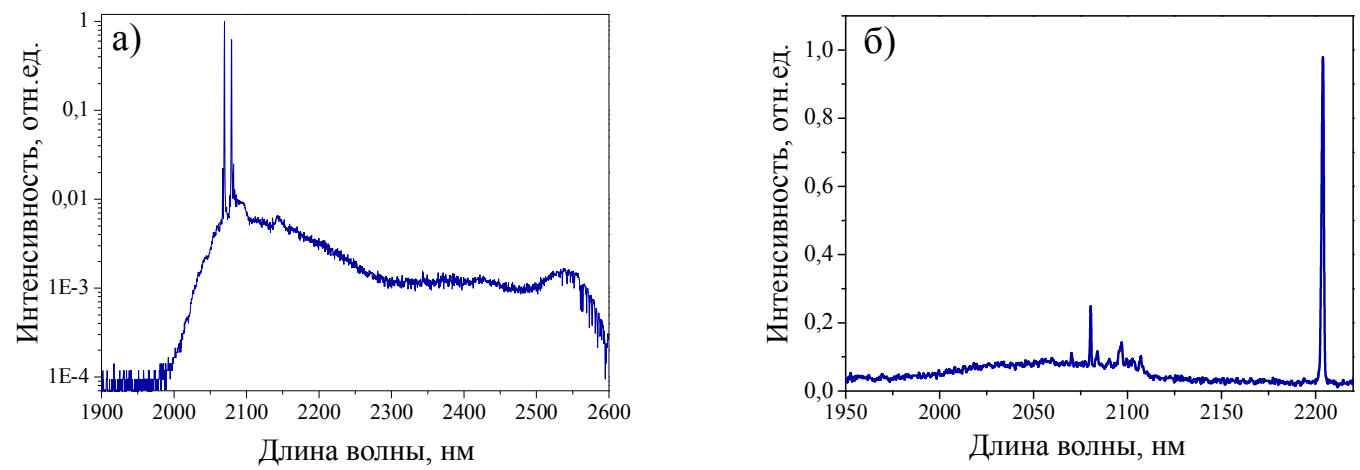

Рис. 2 (а) - Суперконтинуум, полученный в линейной схеме, (б) - усиленная спектральная компонента на длине волны 2.2 мкм.

На Рис. 2 продемонстрированы спектры суперконтинуума, полученного в точке А (рис.1) и усиленная выделенная спектральная компонента на длине волны 2.2 мкм (точка Б, рис. 1).

Таким образом, источники СК, построенные на основе волокон, легированных ионами гольмия позволяют решить ряд задач в спектральном диапазоне 2-3 мкм, при этом сохраняя технологичность ближнего ИК диапазона.

Работа выполнена при поддержке Президиума Российской Академии Наук в рамках программы фундаментальных исследований № I.7 «Актуальные проблемы фотоники, зондирование неоднородных сред и материалов».

\section{Литература}

[1] Y. S. Rumala, R. Dorsinville et al. Springer,. C. 405-424 (2016);

[2] M. N. Petrovich et al. Optics express. T. 21. №. 23. C. 28559-28569 (2013);

[3] H. Takara et al., Electronics Letters. T. 41. №. 5. C. 270-271 (2005);

[4] I. Hartl, X. D. Li, et al. Opt. Lett.,26, 608-610 (2001). 